\title{
Evaluation of the Automated QIAsymphony SP/ AS Workflow for Cytomegalovirus DNA Extraction and Amplification from Dried Blood Spots
}

\author{
Daniela Spalletti-Cernia $^{a}$ Sara Barbato $^{a}$ Rosanna Sorrentino ${ }^{a}$ \\ Luca Vallefuoco $^{a}$ Caterina Rocco $^{a}$ Pasquale Di Costanzo ${ }^{a}$ \\ Antonella Giannattasio ${ }^{a}$ Francesco Raimondi $^{a}$ Claudia Mazzarella ${ }^{a}$ \\ Roberta De Mattiab Giuseppe Portella ${ }^{a}$ \\ ${ }^{a}$ Dipartimento di Scienze Mediche Traslazionali, Università Federico II Napoli, Naples, and ${ }^{\text {b }}$ Qiagen SRL, \\ Milan, Italy
}

\section{Keywords \\ Human cytomegalovirus · Congenital infection · Dried blood spot $\cdot$ Real-time polymerase chain reaction}

\section{Abstract}

Objective: Human cytomegalovirus (CMV) can be considered the most important agent of congenital infection. Long-term sequelae of congenital infection occur in about $15 \%$ of infants asymptomatic at birth. To avoid long-term sequelae or to reduce their burden, it is necessary to identify infected children for early interventions. CMV DNA can be detected in dried blood spots (DBSs). DBSs have been used in several studies for the retrospective diagnosis of congenital CMV (CCMV). It has been proposed to use DBSs for the newborn screening of CMV infection; however, manual methods are not suitable for newborn screening of CCMV. Methods: We evaluated in an off-label application the use of an automated instrument, the QIAsymphony SP/AS, in combination with the artus CMV QS-RGQ kit and the RotorGene $Q$ real-time polymerase chain reaction system. Results: We analyzed 100 DBSs from newborns positive or negative for plasma CMV DNA with a $94 \%$ concordance in positive sam- ples. Conclusions: We show that the QIAsymphony SP/AS and RotorGene $\mathrm{Q}$ workflow is suitable for CMV DNA extraction and detection from DBSs and that the system correctly identified newborns at risk of late sequelae due to CMV infection.

(c) 2017 S. Karger AG, Basel

\section{Introduction}

Cytomegalovirus (CMV) infection is a major viral cause of intrauterine infection with a prevalence ranging from 0.2 to $1.2 \%$ of all births [1]. Human CMV (HCMV) can be considered the most important agent of congenital infection. Most of the children congenitally infected are asymptomatic at birth, whereas a few have severe neonatal disease, with hematological, neurological, and developmental damages $[1,2]$. Children with neonatal disease also suffer from long-term sequelae; these include hear-

Daniela Spalletti-Cernia and Sara Barbato contributed equally to this work.

\section{KARGER}

E-Mail karger@karger.com

www.karger.com/int
(C) 2017 S. Karger AG, Basel

0300-5526/17/0594-0211\$39.50/0
Giuseppe Portella

Dipartimento di Scienze Mediche Traslazionali

University of Naples Federico II - AOU Federico II

Via S. Pansini 2, IT-80131 Naples (Italy)

E-Mail portella@unina.it 
ing defects and mental retardation [3]. In most cases development of asymptomatic infants is normal; however, long-term sequelae occur in about $15 \%$ of the cases. Sensorineural hearing loss is the most common sequela [2].

Overall about $30 \%$ of newborns with congenital CMV infection (CCMV) symptomatic at birth and $10 \%$ of asymptomatic newborns face a significant risk of developing sequelae including hearing loss [2], and it is necessary to identify infected children for early interventions, in order to protect speech and language development.

Differently to CCMV, perinatal CMV infection is acquired at birth or through breast-feeding and does not cause CNS damage. It is difficult to distinguish between CCMV and perinatal CMV infection because the diagnosis of CCMV can be made in children only if urine, saliva or blood samples are available within 21 days after birth [3].

In many countries, dried blood spots (DBSs) are routinely taken a few days after birth for the screening of congenital diseases such as phenylketonuria, hypothyroidism, cystic fibrosis, etc. and stored for prolonged periods of time or indefinitely [3].

CMV DNA can be detected in DBSs [4-8], and DBSs have been used in several studies for the retrospective diagnosis of CCMV [9-11]. Therefore, a screening for CCMV using stored DBSs has been proposed [9]. However, a variety of methods for the extraction of CMV DNA and subsequent detection from DBSs have been employed [10-13], and great differences in sensitivity have been reported. In unselected newborn populations the sensitivity ranges from 28 to $80 \%$ [12-15], a sensitivity of about $30 \%$ has been reported in a very large study [12]; however, in this study only one 8-mm blood spot was used for the testing. A meta-analysis of 15 studies ( $n=26,007$ neonates) has evaluated the performance of DBS real-time polymerase chain reaction (PCR) tests in screening for CCMV infection showing a better sensitivity. The rates of detection of CMV DNA in DBSs from symptomatic and asymptomatic neonates were similar, 95.90 and $96.67 \%$, respectively [16].

In most studies known blood volumes were spotted onto DBSs in a laboratory setting, rather than using actual DBSs, in which the precise volume is not known, and the data obtained were not compared with CMV DNA viral load. Since the use of DBSs for the newborn screening of CCMV infection could represent a useful tool for early intervention $[7,9]$, improvements are required to increase the sensitivity and specificity of CMV DNA testing in the setting of congenital disease screening. Moreover, extraction of CMV DNA from DBSs needs to be automated for higher throughput and lower cost, as manual methods offer only a low throughput, are labor intensive, not cost effective and overall not suitable for newborn screening of CCMV.

In the present study we evaluated, as an off-label application, the use of an automated instrument, the QIAsymphony SP/AS, in combination with the artus CMV QS-RGQ kit and the RotorGene Q PCR system. The QIAsymphony SP/AS instrument can process up to 96 samples in a single run and is suitable for standardized sample preparation and PCR setup. We show that the QIAsymphony SP/AS and RotorGene Q workflow is suitable for CMV DNA extraction and detection from DBSs and that the system correctly identified newborns at risk of late sequelae due to CMV infection.

\section{Patient and Methods}

\section{Patients and DBS Preparation}

We analyzed a total of 100 DBSs, collected in the neonatal intensive therapy unit of AOU Federico II, Naples, between October 2012 and January 2015. All the newborns had a suspected CCMV infection. Urine and blood samples were obtained for the assessment of CMV DNA levels in both plasma and urine. On the basis of CMV DNA plasma levels newborns were divided into 2 groups. The first group included 35 newborns positive for both plasma and urine CMV DNA testing. In this group gestational age was between 34 and 40 weeks; only 1 infant had a gestational age of 26 weeks.

The second group included 65 newborns with negative results for the presence of the viral DNA in plasma. In this second group, CMV DNA testing of urine samples collected within 21 days from birth indicated a congenital infection in 2 infants, whereas in all other infants urine testing gave negative results.

DBSs obtained from both groups were analyzed, and the results were compared with those obtained from plasma samples. Plasma CMV viral load was evaluated using the QIAGEN artus CMV QSRGQ kit. DBSs were collected 3-4 days after birth, at the latest by the second week of life, by pricking the heel and stored at $+4^{\circ} \mathrm{C}$. The study was approved by the Ethical Committee for Biomedical Research of the University Federico II, Naples (ref. 226/13).

DBSs prepared in our laboratory were obtained by spotting 50 $\mu \mathrm{L}$ of blood aliquots or standard aliquots on Guthrie cards. DBSs were kept at room temperature for $24 \mathrm{~h}$, before storage at $+4^{\circ} \mathrm{C}$.

\section{DNA Extraction and Real-Time PCR}

For DNA extraction and amplification of CMV DNA spotted on Guthrie cards, blood spots were excised from DBSs and eluted with $600 \mu \mathrm{L}$ of ATL lysis buffer and $30 \mu \mathrm{L}$ of proteinase $\mathrm{K}(600$ $\mathrm{mAU} / \mathrm{mL}$ ) at $56^{\circ} \mathrm{C}$, for $30 \mathrm{~min}$. The blood spot excised from DBSs differed in size, therefore not always $50 \mu \mathrm{L}$ of blood were used for the extraction.

The resulting eluate was then recovered and transferred into a 2-mL tube for viral DNA extraction. To avoid contamination, scissors used for cutting the blood spots were cleaned with $0.1 \mathrm{M}$ hy- 
drochloric acid between cards, and to detect any contamination, in each extraction session, DBSs without blood spots starting from the elution step were included.

Sample extraction was performed automatically on the QIAsymphony SP/AS platform, using the QIAsymphony DNA mini kit in combination with the artus CMV QS-RGQ kit on the RotorGene Q system. The QIAsymphony SP/AS system performs all steps of the purification procedure and preparation of eluate and master mix for CMV DNA amplification. Each DBS extract was used for real-time PCR duplicate testing; in case of contrasting results the test was repeated. Amplification and melting curves were carefully evaluated to exclude false amplification signals.

\section{Assessment of Linearity and Sensitivity}

Linearity and sensitivity were assayed preparing dilutions of the 1st WHO International standard for HCMV at a concentration of $5 \times 10^{6} \mathrm{IU} / \mathrm{mL}$. Briefly the standard was serially diluted in TrisEDTA buffer from 1:5 up to $1: 5,000,000 ; 50 \mu \mathrm{L}$ of each dilution were spotted in triplicate onto Guthrie cards. Elution from the DBS, DNA extraction and amplification were performed as previously reported. The aim was to assess the lowest dilution of the HCMV DNA standard which was both detectable and quantifiable.

In addition, $2 \mathrm{HCMV}$-positive samples were also diluted in a whole-blood matrix (up to 1:4,096), spotted on Guthrie cards and treated as the other DBSs to assess the minimum amount of HCMV DNA detectable and quantifiable.

\section{Results}

First, we evaluated the sensitivity of the method evaluating dilutions in Tris-EDTA of the 1st WHO International standard for HCMV spotted in DBS. As shown in Figure 1, threshold curve values decrease with the increase in DNA amounts in a linear proportion from 10 to $500,000 \mathrm{IU} / \mathrm{mL}$. The sensitivity in this standard assay was assessed as about $10 \mathrm{IU} / \mathrm{mL}$, with concentrations being lower considered below the limit of detection of this workflow. The stock standard and 1:100 dilutions were amplified in duplicate. The threshold curve mean values were 19.65 and 25.68 , respectively, closely corresponding to the expected values. The data obtained show a strong correlation between DBS extraction and expected CMV DNA values. In fact, the entire procedure of purification and amplification was closely correlated with the total yield for each point of the curve, as shown in Figure 1. To better evaluate the sensitivity of the assay, we used dilutions of HCMV-positive blood samples spotted in duplicate onto Guthrie cards. After extraction and amplification, the sensitivity of the assay was assessed as $245 \mathrm{IU} /$ $\mathrm{mL}$ with 2 positive results (Table 1 ).

Next, we analyzed in duplicate 35 DBSs obtained from newborns positive for plasma CMV DNA. In 29 new-

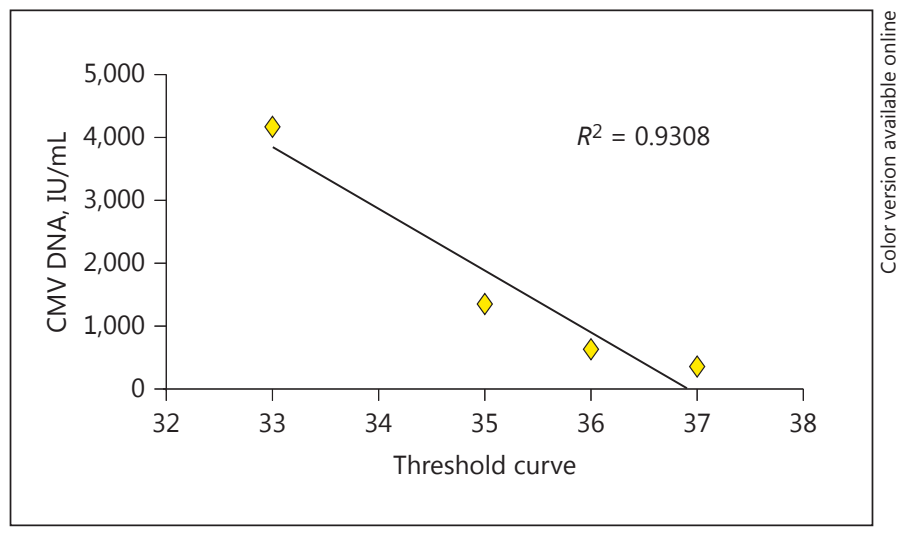

Fig. 1. Analysis of sensitivity on dilutions of the international standard for HCMV spotted in DBSs. Standard and 1:100 dilutions were extracted and amplified in duplicate. A strong correlation between DBS extraction and expected CMV DNA values was obtained.

Table 1. Sensitivity of the DBS assay

\begin{tabular}{lcc}
\hline Dilutions & TC & CMV DNA, IU/mL \\
\hline $1: 2$ & 33 & 3,120 \\
$1: 4$ & 35 & 1,001 \\
$1: 8$ & 36 & 473 \\
$1: 16$ & 37 & 245 \\
\hline
\end{tabular}

TC, threshold curve. To evaluate the sensitivity of the assay, HCMV-positive blood samples were diluted as indicated, and spotted in duplicate onto Guthrie cards. After extraction and amplification, the sensitivity of the assay was assessed as the lowest dilution yielding 2 positive results $(245 \mathrm{IU} / \mathrm{mL})$.

borns, a plasma viral load ranging from 405 to 567,440 $\mathrm{IU} / \mathrm{mL}$ was observed whereas in 6 newborns a low plasma viral load $\leq 278.8 \mathrm{IU} / \mathrm{mL}$ was reported. CMV DNA in urine was ranging from $\leq 170$ and $13.1 \times 10^{7}$ copies $/ \mathrm{mL}$; a correlation with plasma levels was not observed.

In DBSs obtained from high plasma viral load newborns, the CMV DNA was clearly detected in duplicate testing. This observation confirms that it is possible to detect the CMV DNA with the automated extraction, when plasma CMV values are $\geq 405 \mathrm{IU} / \mathrm{mL}$. Triplicate testing was performed in DBSs obtained from newborns with a low viral load; in 5 of them, the triplicate testing gave at least 1 positive result whereas for the remainder CMV DNA was not detected. The concordance between the results obtained evaluating CMV DNA from DBSs and plasma viral load was $94 \%$ (33/35; Table 2); the same 
Table 2. Total of 35 positive plasma CMV samples from infants analyzed by the DBS assay

\begin{tabular}{llll}
\hline & DBS test I & DBS test II & DBS test III \\
\hline 29 infants $(405-567,440 \mathrm{IU} / \mathrm{mL})^{1}$ & positive & positive & NT \\
4 infants $(<278.8 \mathrm{IU} / \mathrm{mL})$ & positive & negative & positive \\
1 infant $(<278.8 \mathrm{IU} / \mathrm{mL})$ & positive & negative & negative \\
1 infant $(<278.8 \mathrm{IU} / \mathrm{mL})^{2}$ & negative & negative & NT \\
\hline
\end{tabular}

NT, not tested. ${ }^{1}$ CMV DNA levels were assessed in these newborns, with values ranging from $\leq 170$ to $13.1 \times 10^{7}$ copies $/ \mathrm{mL} .{ }^{2}$ Urine CMV DNA levels in this newborn were $\leq 170$ copies $/ \mathrm{mL}$. concordance was obtained comparing DBS and urine CMV DNA testing.

DBSs from 65 infants negative for plasma CMV DNA were also analyzed. In 43/65 DBSs, a negative result was obtained in duplicate, and no further testing was performed. In 9 DBSs 2 positive results were obtained, and the analysis of the threshold curve indicated a weak positivity for CMV DNA at values around the detection limit of the assay. Urine of 2 infants tested positive for CMV DNA (with $5 \times 10^{5}$ and $7 \times 10^{3}$ copies/mL, respectively); DBSs collected from these 2 newborns were among the positive DBSs.

DBSs showing a discordant result were tested for a third time; in 10 cases, a negative result was obtained. In 3 DBSs a positive result was obtained (Table 3). It is worth noting that during the study, plasma and urine samples of these infants were collected again, and low plasma levels of CMV DNA were detected, suggesting a CMV infection. However, these additional samples were obtained after 21 days from birth, therefore it is not possible to exclude a postnatal CMV infection.

\section{Discussion}

CCMV infection causes long-term sensorineural hearing loss and neurological impairment, and there is a need to identify infected children for early interventions [3]. Newborn screening for CCMV using DBS has been proposed $[7,9]$.

Studies reporting detection of CMV from DBS have already been performed $[6,7,12,16-19]$. However, methods reporting the highest sensitivities for CMV DNA detection from DBS are not suitable for high-throughput screening being labor intensive and not cost effective.

In the present study, we demonstrated that the automated DNA extraction instrument QIAsymphony SP/AS for CMV DNA extraction and the artus CMV QS-RGQ
Table 3. Total of 65 negative plasma CMV infants analyzed by DBSs

\begin{tabular}{clll}
\hline & DBS test I & DBS test II & DBS test III \\
\hline 43 infants & negative & negative & not performed \\
9 infants $^{1}$ & positive & positive & not performed \\
10 infants & positive & negative & negative \\
3 infants & positive & negative & positive \\
\hline
\end{tabular}

${ }^{1}$ Among these 9 infants there are 2 cases of congenital infection with CMV DNA-positive urine.

real-time PCR kit could be used to identify newborns at risk for late sequelae starting from DBSs, albeit in an offlabel manner. The use of an automated instrument allowed us to perform the testing with a reduced turnaround time (about $40 \mathrm{~min}$ ); however, manual work was required to perform the pretreatment and pipetting of the eluate (about $60 \mathrm{~min}$ ).

Using this method it is possible to detect CMV DNA in DBSs obtained from dilutions of CMV-positive whole blood down to a DNA concentration of about $223 \mathrm{IU} / \mathrm{mL}$. This has been confirmed by the evaluation of DBSs obtained from CMV-infected newborns.

In newborns with plasma CMV DNA viral loads ranging from 410 to $567,440 \mathrm{IU} / \mathrm{mL}$, positive results were obtained in duplicate, whereas DBS analysis in newborns with CMV DNA levels $<278 \mathrm{IU} / \mathrm{mL}$ gave 2 positive results in 4 cases and in 1 case only 1 positive result. The CMV DNA load in these newborns is close to the lower detection limit of the assay. We report a correlation of about $94 \%$ with the analysis of CMV DNA plasma levels.

In newborns with CMV DNA levels $<278 \mathrm{IU} / \mathrm{mL}$, repeated testing was required to detect the presence of CMV DNA. To detect all infected newborns, including those with low levels of CMV DNA, it is important to increase the sensitivity of the detection methods. In our 
study, CMV DNA had been obtained from 2 blood spots with unknown blood volume. DBS samples are by definition small-volume collections with only $10-80 \mu \mathrm{L}$ of blood available for analysis. It is conceivable that the use of 3 or more blood spots could increase the sensitivity of the assay, allowing the correct identification of infected infants. Moreover, it would be advisable to standardize the blood volume used for DNA extraction to around 50 $\mu \mathrm{L}$. To enhance the sensitivity of the assay, duplicate testing could also be performed. However, in newborns with a CMV DNA load near the detection limit, we have observed a discordant result in duplicate testing, therefore triplicate testing of DBSs could further enhance the sensitivity and improve the efficacy of the screening procedure.

Studies have shown that the levels of CMV viremia correlate with the future sensorineural hearing loss [20, 21 ], and a sigmoid relationship has been proposed for the severity of sensorineural hearing loss versus CMV viral load at birth [11]. Accordingly, a test without $100 \%$ analytical sensitivity could be acceptable for the purposes of CMV infection screening, allowing the identification of infected newborns more likely to develop late sequelae.

Our data show the presence of CMV DNA in all DBSs obtained from newborns with $>410 \mathrm{IU} / \mathrm{mL}$, indicating that the QIAsymphony SP/AS instrument in combination with the artus CMV QS-RGQ kit could be useful to identify newborns at high risk for late sequelae of CMV. Moreover, this diagnostic system is already available as a CE-IVD assay for the monitoring of CMV viral load in EDTA plasma or whole blood, and therefore DBS screening for CMV infection could be easily implemented.

A rapid, single-tube nested PCR method has been described and compared with real-time PCRs for sensitivity and specificity [7]. In this study a total of 26 DBSs from infected children were evaluated, and the single-tube nested assay had a sensitivity of 81 with $100 \%$ specificity. In this study the authors also used the QIAsymphony SP instrument for DNA extraction.

Positive results were obtained in CMV plasma-negative newborns. However, in 2 cases urine CMV DNA testing on urine samples collected within 21 days from birth confirmed CCMV infection. In another 3 cases, an additional plasma sample was collected during the study and tested positive for CMV DNA. Therefore, in these 5 cases the positive result can be explained with a true and active CMV infection, either congenital or perinatal. The discrepant result between plasma and DBS can be explained with the different sensitivity of the CMV DNA assay on plasma or whole blood, as the whole-blood CMV DNA detection is more sensitive with respect to plasma CMV DNA detection [22, 23].

The other discordant results can be due to a contamination. We avoided all the potential risks of sample contamination in the laboratory; however, it is not possible to exclude a false-positive result due to a contamination of DBSs during collection or storage. To reduce the possibility of false-positive results due to contaminations, appropriate procedures for the collection, storage, and detection need to be identified. The use of automated punchers and instruments for DBS elution could be useful to reduce the risk of sample contaminations.

Moreover, in order to discriminate between false- and true-positive results it could be advisable to confirm positive samples using a different CMV DNA detection assay (different manufacturer or in-house real-time PCR tests).

In conclusion, the automated DNA extraction and liquid handling instrument QIAsymphony SP/AS could be used for CMV DNA extraction and amplification from DBSs. The high throughput of the instrument could allow a large number of DBSs to be analyzed for the screening of CCMV infection.

\section{Acknowledgments}

The study has been supported by Qiagen SRL. We are indebted to Dr. Gavin Wall for critical reading of the manuscript.

\section{Disclosure Statement}

The authors have no conflicts of interest to declare.

\begin{tabular}{|c|c|}
\hline References & $\begin{array}{l}1 \text { Kenneson A, Cannon MJ: Review and meta- } \\
\text { analysis of the epidemiology of congenital cy- } \\
\text { tomegalovirus (CMV) infection. Rev Med Vi- } \\
\text { rol 2007; 17:253-276. } \\
2 \text { Dollard SC, Grosse SD, Ross DS, et al: New } \\
\text { estimates of the prevalence of neurological } \\
\text { and sensory sequelae and mortality associated } \\
\text { with congenital cytomegalovirus infection. } \\
\text { Rev Med Virol 2007;355:63-17. } \\
3 \text { Karltorp E, Hellström S, Lewensohn-Fuchs I, } \\
\text { et al: Congenital cytomegalovirus infection - } \\
\text { a common cause of hearing loss of unknown } \\
\text { aetiology. Acta Paediatr 2012;101:357-362. } \\
4 \text { Shibata M, Takano H, Hironaka T, et al: De- } \\
\text { tection of human cytomegalovirus DNA in } \\
\text { dried newborn blood filter paper. J Virol } \\
\text { Methods 1994;46:279-285. }\end{array}$ \\
\hline
\end{tabular}


5 Barbi M, Binda S, Primache V, et al: Cytomegalovirus DNA detection in Guthrie cards: a powerful tool for diagnosing congenital infection. J Clin Virol 2000;17:159-165.

6 De Vries JJ, Barbi M, Binda S, et al: Extraction of DNA from dried blood in the diagnosis of congenital CMV infection. Methods Mol Biol 2012;903:169-167.

7 Atkinson C, Emery VC, Griffiths PD: Development of a novel single tube nested PCR for enhanced detection of cytomegalovirus DNA from dried blood spots. J Virol Methods 2014; 196:40-44.

8 Piccirilli G, Chiereghin A, Gabrielli L, Lazzarotto T: Diagnosis and monitoring of cytomegalovirus infection by the quantification of viral load in dried blood spots samples. Expert Rev Mol Diagn 2014;14:139-142.

9 Barbi M, Binda S, Caroppo S: Diagnosis of congenital CMV infection via dried blood spots. Rev Med Virol 2006;16:385-392.

10 Vauloup-Fellous C, Ducroux A, Couloigner $\mathrm{V}$, et al: Evaluation of cytomegalovirus (CMV) DNA quantification in dried blood spots: retrospective study of CMV congenital infection. J Clin Microbiol 2007;45:38043806.

11 Walter S, Atkinson C, Sharland M, et al: Congenital cytomegalovirus: association between dried blood spot viral load and hearing loss. Arch Dis Child Fetal Neonatal Ed 2008;93: 280-285.
12 Boppana SB, Ross SA, Novak Z, et al: Dried blood spot real-time polymerase chain reaction assays to screen newborns for congenital cytomegalovirus infection. JAMA 2010;303: 1375-1382.

13 De Vries JJ, Claas EC, Kroes AC, et al: Evaluation of DNA extraction methods for dried blood spots in the diagnosis of congenital cytomegalovirus infection. J Clin Virol 2009; 46:S37-S42.

14 Johansson PJ, Jonsson M, Ahlfors K, et al: Retrospective diagnostics of congenital cytomegalovirus infection performed by polymerase chain reaction in blood stored on filter paper. Scand J Infect Dis 1997;29:465-468.

15 Yamamoto AY, Mussi-Pinhata MM, Pinto PC, et al: Usefulness of blood and urine samples collected on filter paper in detecting cytomegalovirus by the polymerase chain reaction technique. J Virol Methods 2001;97:159164.

16 Wang L, Xu X, Zhang H, Qian J, Zhu J: Dried blood spots PCR assays to screen congenital cytomegalovirus infection: a meta-analysis. Virol J 2015;12:60-71.

17 Koontz D, Baecher K, Amin M, et al: Evaluation of DNA extraction methods for the detection of cytomegalovirus in dried blood spots. J Clin Virol 2015;66:95-99.
18 Leruez-Ville M, Vauloup-Fellous C, Couderc $S$, et al: Prospective identification of congenital cytomegalovirus infection in newborns using real-time polymerase chain reaction assays in dried blood spots. Clin Infect Dis 2011; 52:575-581.

19 Göhring K, Dietz K, Hartleif S, et al: Influence of different extraction methods and PCR techniques on the sensitivity of HCMV-DNA detection in dried blood spot (DBS) filter cards. J Clin Virol 2010;48:278-281.

20 Boppana SB, Fowler KB, Pass RF, et al: Congenital cytomegalovirus infection: association between virus burden in infancy and hearing loss. J Pediatr 2005;146:817-823.

21 Bradford RD, Cloud G, Lakeman AD, et al: Detection of cytomegalovirus (CMV) DNA by polymerase chain reaction is associated with hearing loss in newborns with symptomatic congenital CMV infection involving the central nervous system. J Infect Dis 2005;191: 227-233.

22 Babady NE, Cheng C, Cumberbatch E, et al: Monitoring of cytomegalovirus viral loads by two molecular assays in whole-blood and plasma samples from hematopoietic stem cell transplant recipients. J Clin Microbiol 2015; 53:1252-1257.

23 Costa C, Sidoti F, Mantovani S, et al: Comparison of two molecular assays for detection of cytomegalovirus DNA in whole blood and plasma samples from transplant recipients. New Microbiol 2016;39:186-191. 